\title{
Insulin glycation by methylglyoxal results in native-like aggregation and inhibition of fibril formation
}

\author{
Luis MA Oliveira ${ }^{1,2,3 \dagger}$, Ana Lages ${ }^{1 \dagger}$, Ricardo A Gomes ${ }^{1,4}$, Henrique Neves ${ }^{1}$, Carlos Família ${ }^{1}$, Ana V Coelho ${ }^{4}$ and \\ Alexandre Quintas ${ }^{1 *}$
}

\begin{abstract}
Background: Insulin is a hormone that regulates blood glucose homeostasis and is a central protein in a medical condition termed insulin injection amyloidosis. It is intimately associated with glycaemia and is vulnerable to glycation by glucose and other highly reactive carbonyls like methylglyoxal, especially in diabetic conditions. Protein glycation is involved in structure and stability changes that impair protein functionality, and is associated with several human diseases, such as diabetes and neurodegenerative diseases like Alzheimer's disease, Parkinson's disease and Familiar Amyloidotic Polyneuropathy. In the present work, methylglyoxal was investigated for their effects on the structure, stability and fibril formation of insulin.

Results: Methylglyoxal was found to induce the formation of insulin native-like aggregates and reduce protein fibrillation by blocking the formation of the seeding nuclei. Equilibrium-unfolding experiments using chaotropic agents showed that glycated insulin has a small conformational stability and a weaker dependence on denaturant concentration (smaller m-value). Our observations suggest that methylglyoxal modification of insulin leads to a less compact and less stable structure that may be associated to an increased protein dynamics.
\end{abstract}

Conclusions: We propose that higher dynamics in glycated insulin could prevent the formation of the rigid cross$\beta$ core structure found in amyloid fibrils, thereby contributing to the reduction in the ability to form fibrils and to the population of different aggregation pathways like the formation of native-like aggregates.

\section{Background}

Insulin is a small protein hormone that is crucial for the control of glucose metabolism. It regulates blood glucose levels by indirectly stimulating glucose transport across the cell membrane and by down regulation of enzymes involved in gluconeogenesis. External administration of insulin is critical in Diabetes type I, where autoimmune response causes a progressive and permanent destruction of the insulin-producing cells in the pancreas due to an interplay of environmental and genetic factors [1-3]. Insulin is composed of two polypeptide chains, the A-chain (21 residues) and the B-

\footnotetext{
* Correspondence: alexandre.quintas@gmail.com

+ Contributed equally

${ }^{1}$ Centro de Investigação Interdisciplinar Egas Moniz, Instituto Superior das Ciências da Saúde Egas Moniz, Campus Universitário, Monte da Caparica 2829-511 Caparica, Portugal

Full list of author information is available at the end of the article
}

chain (30-residues) linked together by two disulfide bonds $[4,5]$. In the secretory vesicles of the pancreas the predominant form of insulin is a zinc-coordinated hexamer, formed by the association of three dimers, and stabilized by two to four zinc ions. However, when released into the blood stream, insulin is present in its biologically active form, $i$. e. the monomer [6,7]. Monomeric insulin is an amyloid protein forming amyloid-like fibrils in vitro, which are promoted by elevated temperatures, low $\mathrm{pH}$, and increased ionic strength $[8,9]$. Insulin amyloid-like fibrils are the hallmark of a clinical condition observed in insulin-dependent diabetic patients, called insulin injection amyloidosis [10]. In this pathological condition, full-length insulin molecules are found in fibrillar form at the site of frequent insulin injections $[9,11,12]$. Additionally it was recently shown that serum samples from Parkinson's disease patients display an autoimmune response to insulin oligomers and fibrils 
[13], possibly indicating the presence of insulin aggregates in this disease as well. Insulin fibril formation has also been a limiting factor in long-term storage of insulin for treatment of diabetes. Thus, better understanding of insulin fibrillation mechanisms could lead to new therapeutic strategies, safer handling and more costeffective storage of insulin. Upon fibrillation, insulin undergoes structural changes from a predominantly $\alpha$ helical state to a $\beta$ - sheet rich conformation. The $\alpha$ - to $\beta$-transition appears only to occur upon fibril assembly [14], and recently Vestergaard and co-workers proposed that insulin oligomers have an overall helical shape [15]. Being intimately related with glycaemia, it is likely that insulin may be modified by reactive $\alpha$-ketoaldehydes such as 3-deoxyglucosone, glyoxal and methylglyoxal. These highly reactive compounds have been considered the most accountable for toxicity at high glucose concentrations [16]. In fact, hyperglycemia induces the glycation of insulin in pancreatic $\beta$ cells [17] and glycated insulin is unable to regulate glucose homeostasis in vivo and to stimulate glucose transport and adipose tissue lipogenesis [17]. Protein glycation is a post-folding modification whereby amino groups in lysine and arginine side chains react irreversibly with carbonyl molecules forming advanced glycation end-products (AGE). Glycation exerts profound effects on protein structure, stability and function. AGE formation in proteins is associated to the clinical complications of diabetes mellitus [18], cataracts [19], uraemia [20], atherosclerosis [21] and age-related disorders [22]. Glycated proteins are present in $\beta$-amyloid $(A \beta)$ deposits in Alzheimer's disease [23-25], in Lewy inclusion bodies of $\alpha$-synuclein in Parkinson's disease [26] and in transthyretin amyloid deposits in familial amyloidotic polyneuropathy (FAP) [27]. In all these amyloid pathologies, $\beta$-sheet fibril structure and the presence of AGE are common features, suggesting a possible role for glycation in amyloid formation pathogenesis. Methylglyoxal is the most significant glycation agent in vivo, being one of the most reactive dicarbonyl molecules in living cells. This compound is an unavoidable by-product of glycolysis, arising from the non-enzymatic $\beta$-elimination reaction of the phosphate group of dihydroxyacetone phosphate and $\mathrm{D}^{-}$ glyceraldehyde 3-phosphate [28]. Methylglyoxal irreversibly reacts with amino groups in lipids, nucleic acids and proteins, forming methylglyoxal-derived advanced glycation end-products (MAGE). In $A \beta$, glycation by methylglyoxal promotes the formation of $\beta$-sheets, oligomers and protofibrils and also increases the size of the aggregates [29]. Argpyrimidine is a specific methylglyoxal modification occurring in arginine residues, and was associated with amyloid diseases [27]. However, little is known about the effects of methylglyoxal glycation on the fibrillation of insulin. The aim of this work is to detail the molecular mechanisms of insulin fibril formation in the presence of methylglyoxal, which may be related to insulin toxicity and/or malfunction. We analyzed the effects of methylglyoxal on the structure, stability and fibrillation of insulin in a concentrationdependent manner. Full glycation pattern analysis of insulin showed that a single residue modification reduces insulin fibrillation by blocking the formation of the seeding nuclei and that by contrast, methylglyoxal glycation stabilizes soluble aggregates that retain nativelike structure as showed by circular dichroism experiments.

\section{Results}

\section{Characterization of insulin glycation by methylglyoxal}

Prior to mass spectrometry analysis, non-glycated and glycated insulin were probed using a specific antibody towards methylglyoxal-derived glycation adducts. As shown in Figure 1A, a dose and time dependent glycation is clearly detected. To unequivocally identify glycated peptides and amino acid residues, non-glycated and glycated insulin were digested using chymotrypsin followed by MS and MS/MS analysis. A modified glycated peptide should be exclusively present in the MS spectrum of glycated insulin with a mass value corresponding to the insulin peptide plus the specific mass increment characteristic of a MAGE modification (72 Da for the lysine specific MAGE CEL and 54, 80 and 144 $\mathrm{Da}$ for the arginine-specific MAGE hydroimidazolones, argpyrimidine and tetrahydropirimidine respectively). This information was used to construct an inclusion list of modified peptides to be fragmented by an additional MS/MS experiment using the MALDITOF/TOF instrument. The sequence information thus obtained allowed the unequivocal identification of MAGE-modified peptides and also assignment of specific modified amino acid.

A comparative analysis of peptide mass spectra from the glycated and unmodified insulin reveals noticeable differences with several new peptides appearing exclusively in the glycated insulin (Figure $1 \mathrm{~B}$ and Table 1). To identify MAGE-modified peptides and assign the glycated amino acid residues, the theoretical digestion was performed considering up to three chymotrypsin misscleavages (PeptideMass, Expasy, http://www.expasy.ch/ tools/peptide-mass.html) and added to the resulting peptide masses the mass increment imposed by a MAGE modification (72, 54, 80 and 144 Da). Using this approach, several peptides, appearing only in the peptide mass spectrum of glycated insulin with a specific MAGE mass increment were observed (Figure 1B). For example, the species at $m / z$ of 991.4788 may correspond to the Bchain peptide $41-48$ ( $\mathrm{LVC}^{\mathrm{a} \mid \mathrm{q}} \mathrm{GERGF}$ ) with $\mathrm{m} / z 937.4603$ plus $54.018 \mathrm{Da}$, a mass increase characteristic of a 
A) Anti-MGH modifications

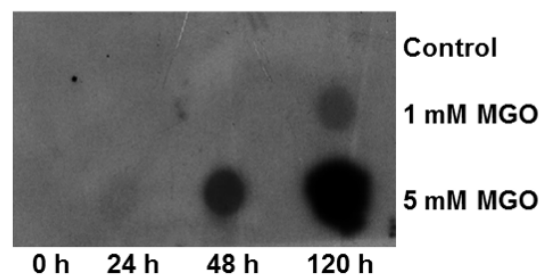

C)

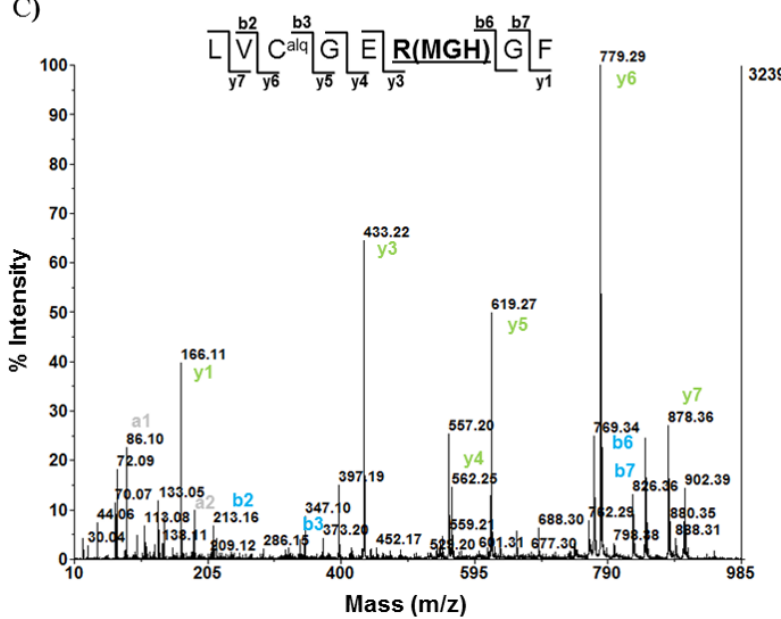

B)

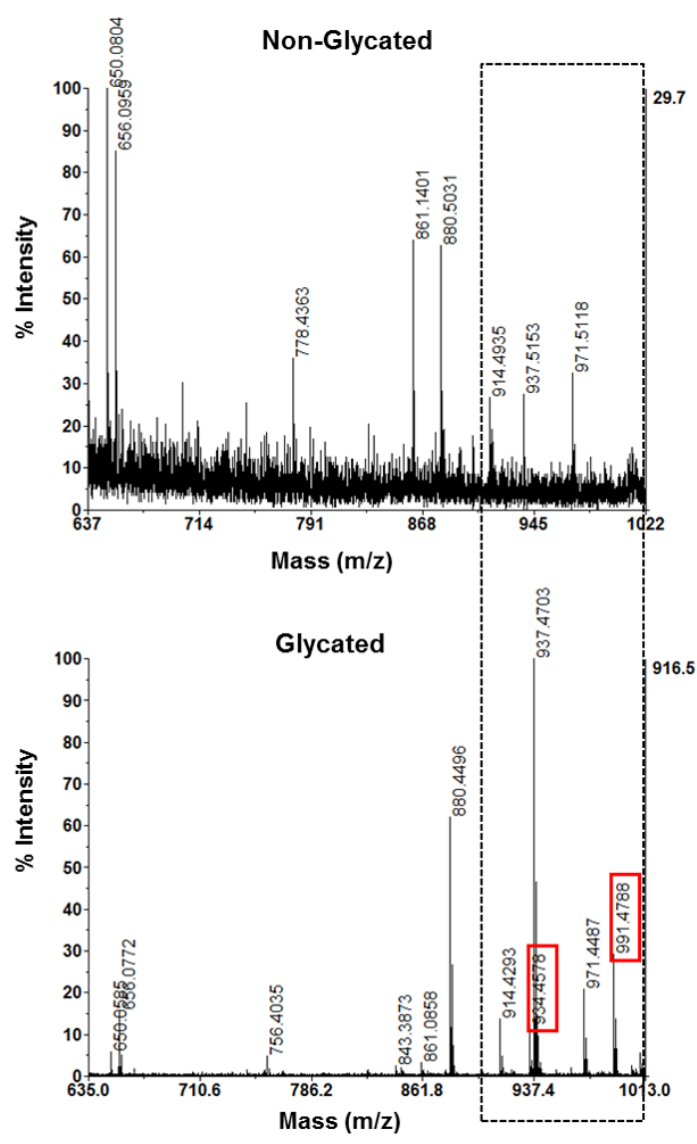

Figure 1 Detection and location of MAGE-modified peptides. (A) Dot-blot analysis with a specific antibody towards methylglyoxal-derived glycation adducts. A dose and time-dependent glycation is clearly detected. (B) The panels show representative sections of the MALDI-TOF/TOF spectra of peptides from unmodified and glycated insulin. New $\mathrm{m} / \mathrm{z}$ peaks, absent from the control, are clearly detected in the mass spectra of the glycated insulin (highlighted in red). These new $\mathrm{m} / \mathrm{z}$ values correspond to the mass of an insulin peptide plus the mass increment characteristic of a hydroimidazolone modification (54 Da). These peptides were analyzed by MS/MS, confirming the glycation of the arginine residue 46. (C) MS/MS spectrum of a glycated insulin peptide with $\mathrm{m} / \mathrm{z}$ 991.4788, showing the $y$ and $b$ fragment ions. The detected fragment ions arise from the amino acid sequence LVC ${ }^{A L Q} G E R G F$, with a hydroimidazolone modification on the arginine residues. All the reported glycated peptides were confirmed by MS/MS data.

Table 1 Assignment of glycated amino acid residues

\begin{tabular}{cccccc}
\hline $\begin{array}{c}\text { Observed } \\
\text { mass } \\
\text { (Da) }\end{array}$ & $\begin{array}{c}\text { Theoretical } \\
\text { mass (Da) }\end{array}$ & $\begin{array}{c}\text { Peptide } \\
\text { sequence }\end{array}$ & $\begin{array}{c}\text { Mass } \\
\text { Increase } \\
\text { (Da) }\end{array}$ & MAGE & $\begin{array}{c}\text { Glycated } \\
\text { residue }\end{array}$ \\
\hline 934.496 & 880.435 & $\begin{array}{c}\text { LVCGERGF } \\
(41-48)\end{array}$ & 54.061 & MGH & R46 \\
\hline 991.521 & 937.456 & $\begin{array}{c}\text { LVC*GERGF } \\
(41-48)\end{array}$ & 54.040 & MGH & R46 \\
\hline 1138.590 & 1084.524 & $\begin{array}{c}\text { LVCGERGFF } \\
(41-49)\end{array}$ & 54.066 & MGH & R46 \\
\hline 1171.590 & 1027.503 & $\begin{array}{c}\text { LVCGERGFF } \\
(41-49)\end{array}$ & 144.087 & THP & R46 \\
\hline 1228.616 & 1084.524 & $\begin{array}{c}\text { LVC } \\
\text { (4VERGFF } \\
(41-49)\end{array}$ & 144.092 & THP & R46 \\
\hline
\end{tabular}

In all cases, the observed peptide mass has a mass increment specific of a methylglyoxal-derived AGE modification. The specific MAGE are indicated in the table and the modified amino acid residues are highlighted in the peptide sequence. (MGH - hydroimidazolone; THP - tetrahydropyrimidine) *peptide with cysteine alquilation. hydroimidazolone (MGH) modification. This strongly suggests that the arginine residue 46 is glycated by methylglyoxal with the formation of a hydroimidazolone. In agreement, the observed peptide with an $\mathrm{m} / \mathrm{z}$ 934.4578 corresponds to the same peptide with a hydroimidazolone at $\mathrm{R} 46$ but without cysteine alquilation $\left(\mathrm{C}^{\mathrm{a}}\right.$ q). To unequivocally confirm these data, MS/MS experiments were performed to provide sequence information. When using the CID fragmentation technique, bond breakage mainly occurs through the lowest energy pathway, that is, the peptide bond, leading to b-ions (when the charge is retained by the amino-terminal fragment) or y-ion (when it is retained by the carboxy-terminal fragment). Thus, if an amino acid residue is modified, the particular y and complementary $b$ ions, which encompasses the modification, will have the particular amino acid mass value plus $54.018 \mathrm{Da}$ for 
hydroimidazolone. Taken the peptide with $\mathrm{m} / \mathrm{z}$ of 991.4788 [LVC ${ }^{\mathrm{a} \mid \mathrm{q}} \mathrm{GER}(\mathrm{MGH}) \mathrm{GF}$ ] (Figure $1 \mathrm{C}$ ), we observed that the mass difference between $y_{1}$ and $y_{2}$ ions corresponds to an $\mathrm{F}$ residue, and the mass difference between $y_{2}$ and $y_{3}$ ions corresponds not to the addition of an $\mathrm{G}$ and $\mathrm{R}$ residue $(57+156 \mathrm{Da})$ but to the addition of $\mathrm{G}$ and $\mathrm{R}$ residue plus the MGH modification on arginine (267 Da in total). The remaining mass differences between consecutive y ions also show this mass increment. The same feature is observed for the b ions. This clearly confirms that the amino acid residue R46 is modified by methylglyoxal. Only modified amino acid residues with confirmed sequence information were considered. Results are summarized in Table 1.

In the end, only the arginine residue in insulin was found to be glycated with the formation of either hydroimidazolone or tetrahydropirimidine. Similar results were observed in a previous study that characterized methylglyoxal modification of insulin. In that study the modification of the arginine residue with a $54 \mathrm{Da}$ mass increase was detected [30]. Even though authors claimed that this mass increase corresponds to a Schiff base formation, this mass increment is characteristic of an MGH advanced glycation end-product. The glycation reactions by methylglyoxal are very fast [31] so the formation of advanced glycation products are expected. In this work, we observed that the arginine residue may also be modified with the formation of a tetrahydropirimidine (mass increment of $144 \mathrm{Da}$ ). This result is in agreement with our previous data showing the inherent heterogeneity of in vitro methylglyoxal glycation reactions [32]. In contrast, no evidences of glycation in the $\mathrm{N}$-terminal and the lysine residue were observed by our mass spectrometry analysis. Although the $\mathrm{N}$-terminal of insulin was found to be the major glycation target when using glucose as glycation agent [33,34], it is well known that methylglyoxal preferentially reacts and modify arginine residues [35].

\section{Methylglyoxal reduces insulin fibril formation}

To investigate the effects of methylglyoxal on insulin fibril formation, insulin was incubated with methylglyoxal at different concentrations in the appropriate aggregation conditions described in the "Methods" section. The insulin fibrillation process as a function of time and methylglyoxal concentration was monitored by ThT fluorescence and circular dichroism (Figure 2). Methylglyoxal glycation of insulin resulted in a substantial dose-dependent decrease in ThT fluorescence intensity at the end of the fibrillation which is consistent with a reduced insulin fibril formation (Figure 2A). These differences were probed not to occur by ThT quenching caused by methylglyoxal or AGEs (Figure 2B). To further explore the biochemical mechanism on the inhibition of fibril formation by methylglyoxal glycation, a kinetic analysis was performed. The fibrillation kinetics represented in Figure 2A exhibit characteristic sigmoidal curves with an initial lag phase, a subsequent growth phase and a final equilibrium phase. Such curves are consistent with a nucleation-dependent polymerization model, in which the lag corresponds to the nucleation phase and the exponential part to fibril growth (elongation) [36-39]. Equation 1 was fitted to the experimental data and yielded values for the fibrillation lag time and for the apparent first-order rate constant $\left(\mathrm{k}_{\mathrm{app}}\right)$ of fibrillation $[40,41]$. The dependence of the kinetic parameters of fibrillation on methylglyoxal concentration is represented in Figure $2 \mathrm{C} 1$ and $2 \mathrm{C} 2$. Clearly, the lag time increases as a function of methylglyoxal concentration, changing from $2.8 \mathrm{~h}$ in unmodified insulin to $9.1 \mathrm{~h}$ upon methylglyoxal glycation. By contrast, no significant changes in the apparent rate constant of fibrillation were observed. These results show a longer nucleation phase which indicates that methylglyoxal glycation blocks the formation of the seeding nuclei, without changing the fibril elongation rate.

To detect changes in protein conformation during the fibrillation process, insulin fibril formation was monitored by circular dichroism (Figure 2D). Insulin presented a mainly $\alpha$-helical secondary structure with spectral local minima at 222 and $208 \mathrm{~nm}$ and a positive band below $200 \mathrm{~nm}$, which are characteristics of $\alpha$-helical conformations (Figure 2 - time $0 \mathrm{~h}$ ). CD spectra collected at several time points along the fibrillation pathway, showed that fibril formation is accompanied by a conformational transition, suggesting loss of $\alpha$-helix and gain of $\beta$-sheet. This shift was most extensive when methylglyoxal was absent and decreases with methylglyoxal in a concentration-dependent manner. These results show that glycation preserves insulin native conformation, blocking the $\alpha$-helix to $\beta$-sheet transition characteristic of amyloid fibril formation. This is in agreement with the reduction of fibril formation observed in ThT kinetic measurements and suggests that there is a structural inertia to conformational changes in glycated insulin that is responsible for blocking the seeding nuclei formation, leading to a reduced fibril formation.

\section{Methylglyoxal induces protein oligomerization}

To investigate the early steps of protein aggregation, samples were collected at indicated incubation times and analyzed by size exclusion chromatography and PAGE (Figure 3). Non-glycated insulin appears as a single molecular species (elution volume of $14.04 \mathrm{ml}$ ) corresponding to the insulin monomer mass. No hexameric insulin species were detected confirming that the insulin sample preparation produced monomeric solution. The 


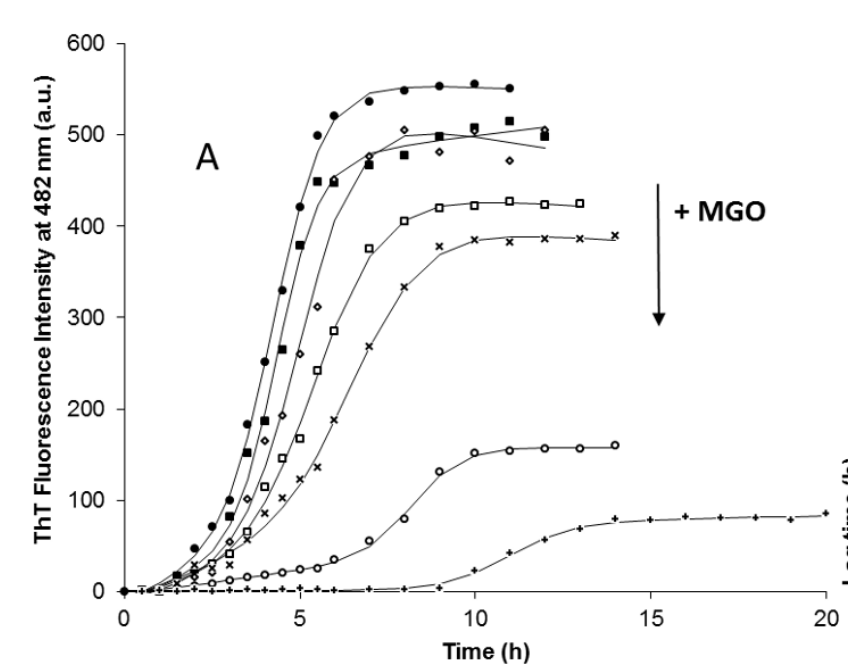

D

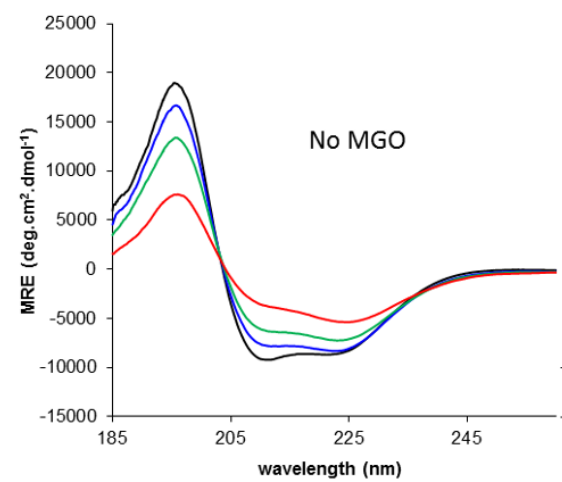

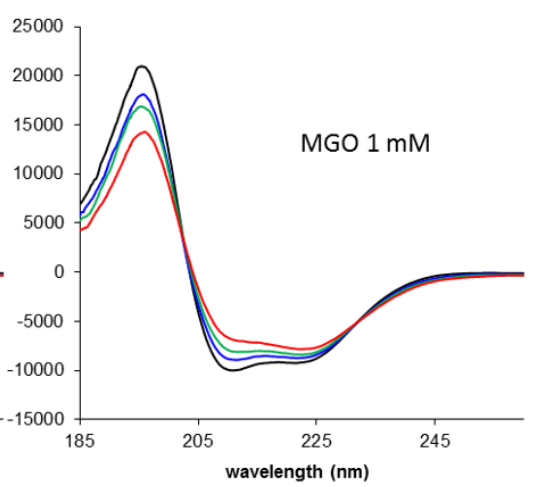
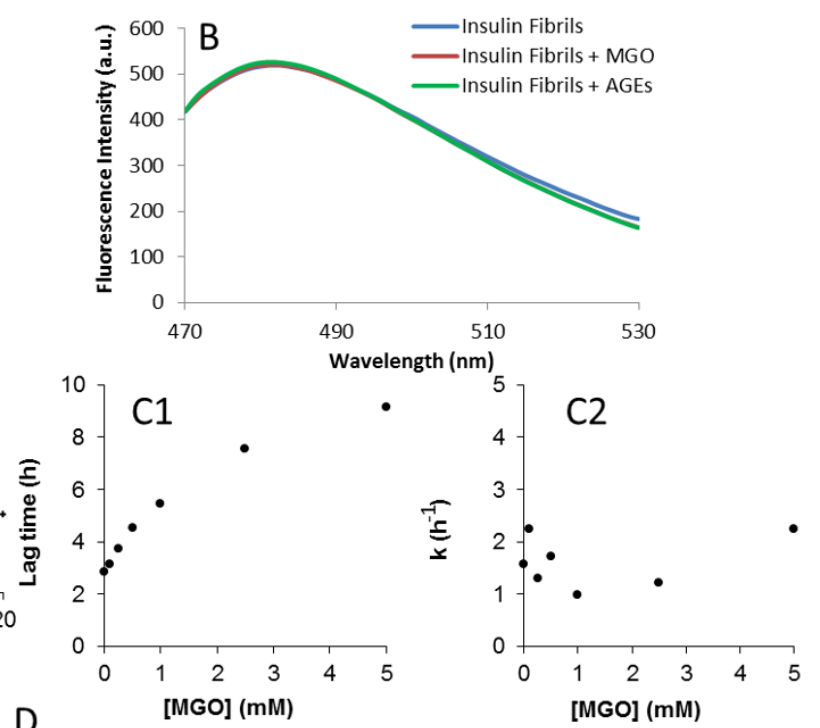

Figure 2 Effect of methylglyoxal concentration on the kinetics of fibril formation of human insulin. (A) Kinetics of fibrillation at different MGO concentrations monitored by ThT fluorescence. The symbols represent the average of ThT fluorescence intensities determined in three experiments, and the lines represent the best fit using the equation 1. Methylglyoxal concentrations used were $0(\cdot), 0.1(\bullet), 0.25(\diamond), 0.5(\square), 1(\times)$, $2.5(0)$ and $5(+) \mathrm{mM}$. The decreasing in fluorescence intensities of the curves plateau are correlated with increasing methylglyoxal concentrations. (B) Evaluation of ThT quenching by methylglyoxal and AGEs. Non-glycated insulin fibrils were probed by ThT fluorescence after 8 h incubation (blue). Subsequently insulin fibrils were mixed with methylglyoxal (red) and glycated insulin containing AGEs (green) and probed again by ThT fluorescence. Fluorescence spectra show no quenching of ThT fluorescence induced by either methylglyoxal (red) or AGEs (green). (C) Dependence of the kinetic parameters lag time $\left(C_{1}\right)$ and apparent rate constant $\left(C_{2}\right)$ as a function of methylglyoxal concentration. Lag time is taken as $x_{0}-2 \tau$ and the $k$ is given by $1 / \tau$. (D) $\alpha$ - to $\beta$ - transition of insulin at the indicated methylglyoxal concentrations during the fibrillation process followed by circular dichroism. CD spectra were collected at time $0 \mathrm{~h}$ (black), $3 \mathrm{~h}$ (blue), $5 \mathrm{~h}$ (green) and $7 \mathrm{~h}$ (red) incubation.

Measurements were all performed at $37^{\circ} \mathrm{C}$ with agitation of the reaction mixture.

same feature was observed for glycated insulin at time 0 (elution volume of $13.68 \mathrm{ml}$ ), as it can be observed either by SEC or gel electrophoresis. The difference in the elution volumes is explained by an increased hydrodynamic radius of glycated insulin, which may be caused by a less compact structure formed upon glycation. During incubation time, the unmodified insulin monomer changes into amyloid fibrils. This can be observed from the native-PAGE (Figure 3B) where a reduction of insulin monomer (only species present at time $0 \mathrm{~h}$ ) concomitant with the appearance of high molecular mass fibrils, unable to enter the separation gel, is clearly detected. Likewise, the insulin amyloid fibrils are unable to pass through the SEC column's filter and enter the stationary phase and thus a reduction of the SEC insulin monomer peak intensity with time is observed (Figure $3 \mathrm{~A})$. Interestingly, intermediate oligomeric species are apparently absent or in undetectable concentration. This may be due to the nature of soluble oligomers: they are intermediates of the aggregation process, and are therefore an extremely transient and labile species [42]. As soon as their concentration reaches a few percent, the oligomers are rapidly converted into amyloid fibrils with an organized $\beta$-structure. A very different scenario 


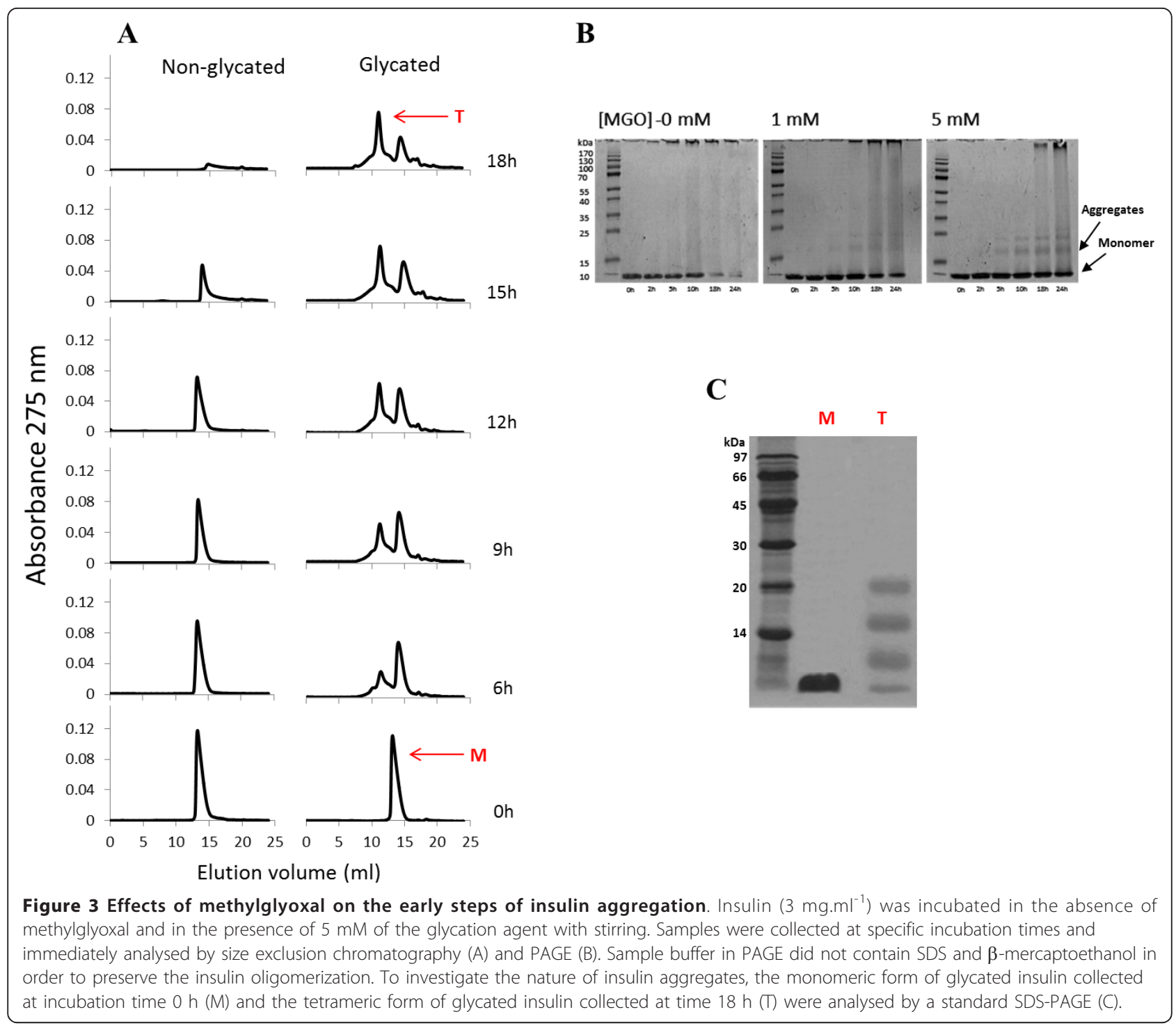

emerged when methylglyoxal is added. In this case, SEC peak intensity also becomes reduced, but other species are clearly detected on the chromatogram, corresponding to insulin soluble aggregates (Figure $3 \mathrm{~A}$ ). These aggregates are also observed in gel electrophoresis and show apparent molecular masses consistent with trimeric and tetrameric forms of insulin (Figure 3B). Moreover, high molecular mass species are only detected in the later incubation times compared to the control (without methylglyoxal). Taken together, these results show that methylglyoxal-induced glycation reduces insulin fibril formation and promotes the population of oligomeric states.

Protein glycation has been referred to induce protein aggregation due to cross-link formation [43,44]. However, when using methylglyoxal, only the lysine-lysine dimer MOLD is formed [45], which is a minor advanced glycation end-product compared to other AGE [46]. The fact that only a single arginine residue is glycated and that significant amounts of glycated insulin are in aggregated forms suggest that major non-covalent interactions are likely to be involved. The nature of the interactions in glycated insulin aggregates was evaluated by SDS-PAGE. The denaturing conditions of the SDSPAGE induced significant dissociation of the glycated insulin tetramer (Figure 3C) showing that mainly noncovalent interactions are present in the insulin aggregates.

\section{Methylglyoxal effects on insulin structure and stability}

Our final set of experiments was aimed to investigate the structural changes imposed by methylglyoxal-derived glycation that might be associated to fibril inhibition and stabilization of oligomeric species. In these 
experiments insulin was incubated without agitation, a condition that does not promote aggregation, as observed by SEC experiments (see Additional File 1: Figure S1). In these conditions, insulin is glycated but remains almost entirely in monomeric form. In contrast with the results obtained when insulin was incubated in aggregation conditions, the $C D$ spectra of non-glycated insulin remains unchanged during the incubation period (Figure 4A), while glycated insulin undergoes slight spectral changes (Figure 4B and 4C). Spectra deconvolution shows a redistribution of secondary structure elements in glycated insulin with a respective increase in $\beta$-sheet content, an increase in unordered structure and a reduction in the relative $\alpha$-helical content (Table 2).

We then assess the conformational stability of glycated and native insulin (Figure 4D and 4E). GdnHCl-induced denaturation was found to be reversible, as judged by
$\mathrm{CD}$ experiments after dialysis of $\mathrm{GdnHCl}$-denatured insulin (data not shown). Fits were made using the linear extrapolation method [47] in a non-linear least squares fitting procedure and yielded values for $\Delta G_{-}^{o}$ $\left(\mathrm{H}_{2} \mathrm{O}\right)$, the conformational stability, and $m$, the dependence of $\Delta G_{-}^{o}$ on denaturant concentration. Table 3 shows the values obtained from the curves in Figure 4D and $4 \mathrm{E}$ for $\Delta G_{-}^{o}\left(H_{2} O\right), m$, and $C m$, the denaturant concentration at the midpoint of the unfolding transition. Glycated insulin has a smaller conformational stability with $\Delta G_{-}^{o}\left(\mathrm{H}_{2} \mathrm{O}\right)$ of $2.66 \pm 0,27 \mathrm{kcal} \cdot \mathrm{mol}^{-1}$ against 3,34 \pm

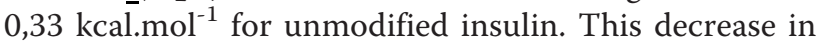
conformational stability is also supported by the smaller $\mathrm{Cm}$ value of glycated insulin. In addition, glycation resulted in a weaker $\mathrm{GdnHCl}$-dependence of unfolding (smaller $m$-value). The $m$-value has been correlated with the difference between accessible surface areas in the

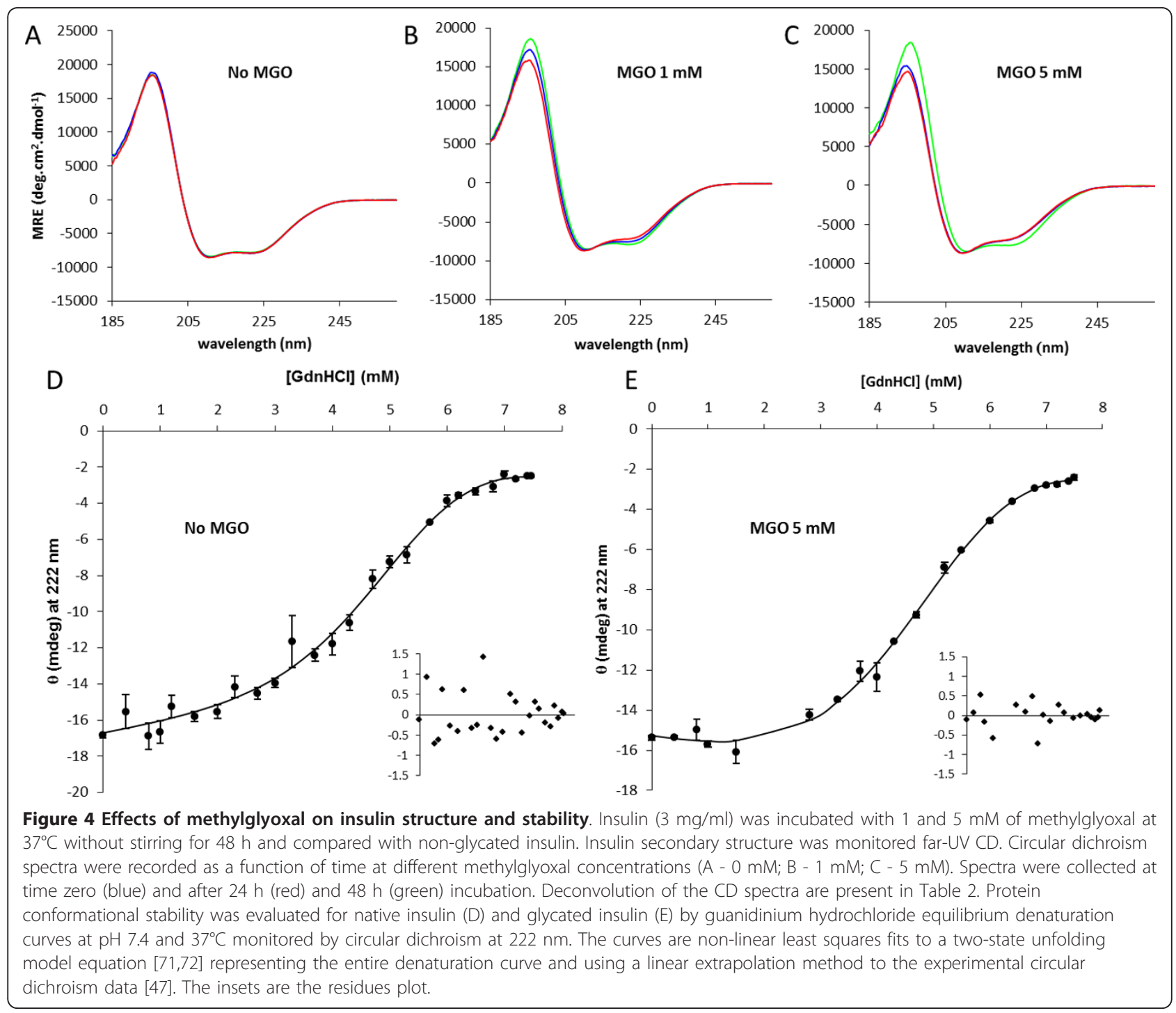


Table 2 Distribution of the structural element fractions for native and glycated insulin along time obtained by deconvolution of CD spectra using CDSSTR algorithm available on Dichroweb (Dichroweb; http://www.cryst.bbk.ac.uk/ cdweb/html/home.html) $[69,70]$

\begin{tabular}{|c|c|c|c|c|c|c|}
\hline [MGO] (mM) & Time (h) & $\alpha$-Helix & $\beta$-Sheet & $\beta$-Turns & Unordered structure & NRMSD \\
\hline \multirow[t]{3}{*}{0} & 0 & 31 & 23 & 22 & 24 & 0.028 \\
\hline & 24 & 33 & 23 & 21 & 23 & 0.033 \\
\hline & 48 & 32 & 22 & 22 & 24 & 0.029 \\
\hline \multirow[t]{3}{*}{1} & 0 & 31 & 24 & 21 & 24 & 0.027 \\
\hline & 24 & 28 & 26 & 22 & 26 & 0.032 \\
\hline & 48 & 24 & 27 & 22 & 27 & 0.036 \\
\hline \multirow[t]{3}{*}{5} & 0 & 32 & 22 & 22 & 24 & 0.022 \\
\hline & 24 & 23 & 27 & 21 & 27 & 0.029 \\
\hline & 48 & 23 & 28 & 21 & 27 & 0.035 \\
\hline
\end{tabular}

The NRMSD parameter represents the normalized root mean square deviance.

unfolded and folded states: $m \propto \Delta \mathrm{A}$, where $\Delta \mathrm{A}=\mathrm{A}_{\mathrm{U}}$ $\mathrm{A}_{\mathrm{N}}$ [48]. This weak dependence may reflect a less compact folded structure or a more compact unfolded state. Putting these results together with the SEC experiments where glycated insulin has a small elution volume then the native insulin, suggest that the presence of a less compact structure is a more likely scenario, which may be the basis of a higher susceptibility to different unfolding and aggregation pathways.

\section{Discussion}

Insulin is a protein hormone that regulates glucose concentration in blood. It is intimately related with glycaemia and is vulnerable to glycation by glucose and other highly reactive carbonyls like methylglyoxal. Additionally, it has the ability to aggregate and form amyloid-like fibrils that are characteristic of a clinical condition called insulin injection amyloidosis [10]. In this work we have investigated the effects of methylglyoxal-modification of insulin on structural and fibril-forming properties. Mass spectrometry data showed that methylglyoxal specifically modifies a single arginine residue in the B-chain. This is in agreement with a previous study that observed a methylglyoxal-derived modification on the arginine residue of the B chain [30]. The glycation of insulin in our experimental conditions promoted the coexistence on insulin molecules with the arginine residue modified to a hydroimidazolone and to a tetrahydropirimidine

Table 3 Thermodynamic parameters from $\mathrm{GdnHCl}$ unfolding studies of native and glycated insulin

\begin{tabular}{cccc}
\hline & $\begin{array}{c}\Delta G^{\mathbf{o}}\left(\mathbf{H}_{\mathbf{2}} \mathbf{O}\right) \\
\left(\mathbf{k c a l} \cdot \mathbf{m o l}^{-\mathbf{1}}\right)\end{array}$ & $\begin{array}{c}\boldsymbol{m} \\
\left(\mathbf{k c a l} \cdot \mathbf{m o l}^{-\mathbf{1}} \cdot \mathbf{M}^{-\mathbf{1}}\right)\end{array}$ & $\begin{array}{c}\mathbf{C m} \\
\mathbf{( M )}\end{array}$ \\
\hline Insulin & $3.34 \pm 0.33$ & $0.63 \pm 0.10$ & $5.31 \pm 0.98$ \\
Glycated Insulin & $2.66 \pm 0.27$ & $0.52 \pm 0.09$ & $5.10 \pm 0.98$ \\
\hline
\end{tabular}

Parameters were obtained by a direct fit of the model equations to experimental data in Figure $4 \mathrm{D}$ and $\mathrm{E} . \Delta G^{\circ}(\mathrm{H} 2 \mathrm{O})$ is the protein conformational stability; $m$ is the dependence of $\Delta \mathrm{G}^{\circ}$ on denaturant concentration; $\mathrm{Cm}$ is the denaturant concentration at the midpoint of the unfolding transition. modification. This heterogeneity in in vitro glycation was already observed [32]. No modification on the lysine residues and $\mathrm{N}$-terminal were detected by our experimental approach. Insulin glycation by $\mathrm{D}^{\text {-glucose also led }}$ to the coexistence of protein molecules glycated at different residues [34]. In opposition to our results, the $\mathrm{N}$ terminus of both chains and the lysine residue 29 were modified upon glucose glycation. This difference is not surprising since it is well documented that methylglyoxal preferentially reacts and modifies arginine residues [35].

Previous reports showed that AGE modifications accelerated the fibrillation of several proteins and peptides including $\beta$-amyloid peptide, tau and albumin $[49,50]$. Additionally, AGE-modified proteins were detected in amyloid deposits from several amyloidosis such as Alzheimer's [24,51], Parkinson's [26,52] disease and FAP [27]. In contrast with those amyloidogenic proteins, modification of $\beta$-2-microglobulin and $\alpha$-synuclein by different glycation agents resulted in inhibitory effects on the formation and extension of fibrils [53,54]. Our data also showed that insulin fibril formation is substantially reduced upon methylglyoxal modification. The observed differences might be a consequence of the inherent properties of the native structure of each protein, or differential structural changes induced by AGE modifications as result of different glycation agents. In most of the cases mentioned above, fibrillation enhancement is achieved by modifying amyloidogenic proteins with glycating sugars like glucose or fructose while small and highly reactive carbonyls like methylglyoxal are apparently more prone to reduce fibril formation. A good example comes from $\alpha$-synuclein where glyoxal and methylglyoxal inhibit fibril formation [54] while $\mathrm{D}^{-}$ ribose glycation does not [55]. This suggests that different glycation agents lead to specific structural constraints that have a major role in protein fibrillation kinetics. 
Insulin offers a structural simplicity of two short polypeptide chains constrained by one intramolecular and two intermolecular disulphide bonds and has wellknown molecular mechanisms of fibril formation $[8,56]$. The insulin B-chain segment with the sequence LVEALYL is the smallest segment in the basis of fibril assembly, being crucial to the cross $-\beta$ spine of the insulin fibril [56]. In full-length insulin molecules, there must be conformational changes for the LVEALYL side chains of the segment to be exposed and to interact with each other [56]. However, insulin glycation leads to nativelike aggregation, as showed by $\mathrm{CD}$ experiments. This suggests that glycation impairs insulin conformational alterations, causing the inhibitory effects observed in the fibrillation process. Moreover our kinetic analysis of insulin aggregation showed an increase in fibrillation lag time. The lag time can be used to monitor the nucleation phase prior to the exponential stage of fibril elongation. Increasing lag time indicates that methylglyoxal glycation inhibits the fibrillation process by blocking the formation of the seeding nuclei. Accordingly fibril formation is reduced due to lack of a critical concentration of seeds.

Despite the inhibition of fibril formation, size exclusion chromatography experiments showed that glycation induces insulin aggregation. However these aggregates are small, soluble, non-fibrillar and native-like in structure, and apparently are not a consequence of a covalent crosslinking of insulin monomers. This implies that aggregation of modified insulin is not a merely result of a chemical reaction, but an outcome of complex folding interactions that are established and populates an offpathway to fibril formation. A subject of intense investigation is whether the amyloid fibril deposits or the prefibrillar aggregates, called protofibrils, are the most potent mediators of cell damage, cytotoxicity and neurotoxicity. The finding that the severity of cognitive impairment in protein misfolding diseases correlates with the levels of small oligomeric species and not with the large fibrillar species has led researchers to the conclusion that the soluble small aggregates are the primary cause of the pathological symptoms [57-60]. Moreover, accumulation of AGE-modified proteins has been related to cellular responses including oxidative stress and the release of pro-inflammatory cytokines mediated by AGE:RAGE interaction $[61,62]$. Therefore it will be interesting to evaluate the cytotoxicity of the insulin glycated aggregates.

In order to understand what structural restrictions could cause this behavior, we investigated the effects of methylglyoxal glycation on the structure and stability of insulin. Circular dichroism experiments showed that modified insulin has a small conformational stability and a slight increase in $\beta$-sheet content when compared to the unmodified protein. This lower conformational stability is accompanied by a weaker dependence of $\Delta \mathrm{G}_{-}^{\mathrm{o}}$ on denaturant concentration which is related to a less compact native structure or a more compact unfolded state [48]. Size exclusion chromatograms of glycated insulin showed a slight decrease in retention time of the insulin monomer, supporting the idea of a less compact native structure. Although most of the proteins have welldefined structures, they are not static molecules. Proteins are dynamic entities and possess an inherent flexibility. Having a lower contribution of van der Waals interactions, it is likely to expect that a less compact structure may result in a more dynamic one. The term dynamics is used for intrinsic protein molecular motions, while the term flexibility is used for the ability of a protein to adapt its structure to external stimuli. Accordingly, proteins are flexible as a consequence of their dynamics, yet their dynamics do not automatically result in flexibility. We propose that higher dynamics in glycated insulin could lead to impairment of the formation of the rigid cross $-\beta$ core structure found in amyloid fibrils, resulting in a higher susceptibility to different unfolding and aggregation pathways. In this case other aggregation pathways that preserve native-like structure and comparable dynamics, like the small and soluble aggregates of glycated insulin observed in size exclusion chromatography, could be more likely populated.

\section{Conclusions}

Insulin is a nearly all-alpha protein playing a central role in blood glucose homeostasis and is associated with a medical condition termed insulin injection amyloidosis, characterized by the formation and deposition of amyloid fibrils from insulin. Due to its main physiological role, insulin is a target for glycation by methylglyoxal. Protein glycation mostly impairs protein functionality by changing protein structure and stability, and AGE-modified proteins have been related to cellular responses including oxidative stress and the release of pro-inflammatory cytokines. Glycation has been associated with human conformational diseases, such as Alzheimer's disease, Parkinson's disease and Familiar Amyloidotic Polyneuropathy, which are associated to the formation of amyloid fibrils. Our results show that glycation of insulin by methylglyoxal reduce insulin fibril formation and leads to the formation of insulin native-like aggregates. In addition they suggest that modification of insulin leads to a less compact and less stable structure that may be associated to an increased dynamics, preventing the formation of the rigid cross $-\beta$ core structure found in amyloid fibrils. Overall the present study points that methylglyoxal adducts can trigger a drifting from an amyloid aggregation to a native-like aggregation pathway, a mechanism that might be important in the 
context of the amyloidogenicity of AGE-modified proteins involved in conformational diseases.

\section{Methods \\ Insulin preparation and glycation}

Insulin exists in solution as an equilibrium mixture of monomers, dimers, tetramers and hexamers, and possibly higher associated states, depending on concentration, $\mathrm{pH}$, metal ions, ionic strength and solvent composition [63]. A solution containing only insulin in the monomeric form was prepared taking into account the fluctuation of its association states in different milieu conditions as described [64]. Briefly, human zinc-free insulin (Sigma) was dissolved in ultra-pure miliQ water to a final concentration of $6 \mathrm{mg} \cdot \mathrm{ml}^{-1}$ and acidified with $\mathrm{H}_{3} \mathrm{PO}_{4}$ to a $\mathrm{pH}$ of 5 in order to obtain monomeric insulin. Insulin at $\mathrm{pH} 5$ was then incubated for $15 \mathrm{~min}$ at room temperature and protein concentration was determined by absorbance at $275 \mathrm{~nm}\left(\varepsilon_{275}=4560 \mathrm{M}^{-1} \mathrm{~cm}^{-1}\right)$ in a UV-Visible spectrophotometer Jasco V-530. Finally, insulin was neutralized to $\mathrm{pH} 7$ with $\mathrm{NaOH} 0.1 \mathrm{M}$ and diluted to a final concentration of $3 \mathrm{mg} \cdot \mathrm{ml}^{-1}$. Insulin preparation was proven to be in the monomeric form after $\mathrm{pH}$ neutralization as evaluated from size exclusion chromatography and native-PAGE experiments as described below. Also circular dichroism experiments showed that no structural changes or unfolding occurred with $\mathrm{pH}$ variations. In all assay, monomeric insulin was prepared in exactly the same way.

For the methylglyoxal-derived glycation of insulin, the protein preparation $\left(3 \mathrm{mg} \cdot \mathrm{ml}^{-1}\right)$ was incubated with methylglyoxal (at several concentrations ranging from 0.1 to $5 \mathrm{mM}$ ) (a kind gift from Dr. Carlos Cordeiro, Centro de Química e Bioquímica, FCUL, Lisbon, Portugal) in $50 \mathrm{mM}$ potassium phosphate buffer, $\mathrm{pH}$ 7.4, supplemented with $150 \mathrm{mM}$ of $\mathrm{NaF}$, at $37^{\circ} \mathrm{C}$ in sterile conditions. Samples were collected at different incubation times for analysis with the maximum incubation time of 48 hours. Control samples were treated in the same way but without methylglyoxal addition. To evaluate the effects of methylglyoxal on insulin stability and secondary structure changes, samples were incubated without stirring, a condition that avoid fibril formation, producing only glycated insulin in the monomeric state. In contrast, for the oligomerization and fibrillation kinetic studies, samples were incubated with vigorous agitation. Aliquots were collected in sterile conditions at defined incubation times from 0 to 4 hours and immediately analyzed.

\section{Characterization of insulin glycation by methylglyoxal using mass spectrometry and dot-blot analysis}

Dot-blot assay was performed using a specific monoclonal antibody towards methylglyoxal-derived glycation (a kind gift from Dr. Ram Nagaraj, Case Western University, Cleveland, OH, USA), using a 1:2000 dilution. Washes, secondary antibody and detection procedures were performed using the BM Chemiluminescence Western Blotting Kit (Pierce) following the manufacturer's instructions.

To characterize the protein modification and assign the amino acid residues modified by methylglyoxal, a chymotrypsin digestion of insulin was performed. Protein samples were reduced with $10 \mathrm{mM}$ dithiothreitol in $100 \mathrm{mM} \mathrm{NH}_{4} \mathrm{HCO}_{3}$ buffer ( $\mathrm{pH} \mathrm{8.0)}$ ) at $55^{\circ} \mathrm{C}$ for $1 \mathrm{~h}$ and alkylated with $55 \mathrm{mM}$ of iodoacetamide in $100 \mathrm{mM}$ $\mathrm{NH}_{4} \mathrm{HCO}_{3}$ buffer ( $\mathrm{pH} 8.0$ ) in the dark for $30 \mathrm{~min}$. In solution digestion were performed with chymotrypsin (Promega) using 50:1 ratio of protein:protease in 100 $\mathrm{mM}$ Tris- $\mathrm{HCl}$ buffer ( $\mathrm{pH}$ 7.8) containing $10 \mathrm{mM} \mathrm{CaCl}$ for $16 \mathrm{~h}$. Protein digestion was stopped by the addition of formic acid [(final concentration of $1 \%(\mathrm{v} / \mathrm{v})$ ]. The obtained peptide mixture was purified and concentrated by solid-phase extraction using home-made R2 Pore microcolumns (Applied Biosystems) as previously described [65]. Peptide mixture were eluted directly onto the MALDI target plate with $0.5 \mu \mathrm{l}$ of $\alpha$-CHCA matrix $\left(5 \mathrm{mg} \cdot \mathrm{ml}^{-1}\right)$ prepared in $50 \%(\mathrm{v} / \mathrm{v})$ acetonitrile with $0.1 \%(\mathrm{v} / \mathrm{v})$ formic acid. The mixture was allowed to air dry (dried droplet method). Sample peptides were analysed in a MALDI-TOF-TOF mass spectrometer 4800 plus (Applied Biosystems) in positive reflectron mode for peptide mass determination. The mass spectrometer was externally calibrated using 4700 Calibration Mix (Applied Biosystems). Mass spectra were collected in a result-independent acquisition mode, typically using 1000 laser shots per spectrum and a fixed laser intensity of $3500 \mathrm{~V}$. The peptides of interest (i.e., having a mass consistent with the mass increment of the modifications by methylglyoxal) were selected for MS/MS experiments using Collision Induced Dissociation (CID), with $1 \mathrm{kV}$ collision energy and an air pressure of 106 torr. Two thousand laser shots were collected for each MS/MS spectrum using a fixed laser intensity of $4500 \mathrm{~V}$. Raw data were generated by the 4000 Series Explorer Software v3.0 RC1 (Applied Biosystems). The identification of MAGE-modified peptide and amino acid residues was further validated using Peaks Studio 4.5 software (Bioinformatic Solutions Inc.), combined with manual inspection of the assigned sequence.

Analysis of insulin-fibril formation and fibrillation kinetics To investigate the effects of MGO in insulin fibril formation, solutions of monomeric insulin (prepared as described above) were incubated with stirring at $37^{\circ} \mathrm{C}$ in the presence of methylglyoxal at $0,0.1,0.25,0.5,1.0,2.5$ and $5.0 \mathrm{mM}$. Fibril formation was monitored with 
thioflavin $\mathrm{T}$ (ThT) binding assay as previously described $[65,66]$. Briefly, aliquots of $5 \mu \mathrm{l}$ were removed and added to $0.5 \mathrm{ml}$ of $10 \mu \mathrm{M}$ ThT in $50 \mathrm{mM}$ sodium phosphate buffer ( $\mathrm{pH}$ 7.4) at room temperature and immediately analyzed. Fluorescence measurements were performed using a Perkin Elmer LS50B spectrofluorimeter, in quartz cuvettes with $1 \mathrm{~cm}$ excitation light path. ThT fluorescence was recorded immediately after ThT binding from 470 to $530 \mathrm{~nm}$ with excitation at 450 $\mathrm{nm}$, an increment of $0.5 \mathrm{~nm}$, an integration time of $1 \mathrm{~s}$ and $5 \mathrm{~nm}$ slits for both excitation and emission. For each sample, the signal was obtained as the ThT intensity at $482 \mathrm{~nm}$ from which was subtracted a blank measurement recorded prior to addition of insulin to the ThT solution. To test if methylglyoxal alone or the derived insulin AGEs interfere with ThT fluorescence of insulin fibrils, non-glycated insulin fibrils were produced in vigorous agitation by incubating monomeric insulin preparation $\left(3 \mathrm{mg} \cdot \mathrm{ml}^{-1}\right)$ in the absence of methylglyoxal for $8 \mathrm{~h}$. ThT fluorescence was then determined for insulin fibrils alone, in the presence of methylglyoxal ( 5 $\mathrm{mM})$, and also in the presence of methylglyoxal-glycated insulin $\left(3 \mathrm{mg} \cdot \mathrm{ml}^{-1}\right)$ prepared with vigorous agitation as described above.

ThT fluorescence measurements were plotted as a function of time and equation 1 was fitted to the experimental data $[40,41]$.

$$
Y=\left(y_{i}+m_{i} x\right)+\frac{\left(y_{f}+m_{f} x\right)}{1+e^{-\frac{x-x_{0}}{\tau}}}
$$

where $\mathrm{Y}$ is the fluorescence intensity and $\mathrm{x}_{0}$ is the time to $50 \%$ of maximal fluorescence. The initial base line during the lag phase is described by $y_{i}+m_{i} x$. The final base line after the growth phase had ended is described by $y_{f}+$ $\mathrm{m}_{\mathrm{f}} \mathrm{x}$. The apparent first-order rate constant $\left(\mathrm{k}_{\mathrm{app}}\right)$ for the growth of fibrils is calculated as $1 / \tau$, and the lag time is calculated as $\mathrm{x}_{0}-2 \tau$. This expression is unrelated to the underlying molecular events, but provides a convenient method for comparison of the fibrillation kinetics.

\section{Size-exclusion and PAGE experiments}

Aggregation of human insulin upon methylglyoxal glycation was monitored by size exclusion chromatography (SEC) and Native-PAGE. Solutions of monomeric insulin were incubated and stirred at $37^{\circ} \mathrm{C}$ in the presence of methylglyoxal at 0,1 and $5 \mathrm{mM}$. Samples were analyzed by SEC at defined incubation times, after filtration with a $0.2 \mu \mathrm{m}$ Whatman filter. SEC was performed with HPLC Jasco PU-2080 Plus isocratic pump with an UV detector JASCO 2075. The mobile phase was $50 \mathrm{mM}$ sodium phosphate buffer pH 7.4 with $150 \mathrm{mM} \mathrm{NaF}$. Separation was achieved on a molecular exclusion analytical column (Amersham-Pharmacia Superdex ${ }^{\mathrm{TM}} 75$ 10/
$300 \mathrm{GL}$ ) at a flow rate of $0.4 \mathrm{ml} / \mathrm{min}$. Eluting peaks were monitored at $275 \mathrm{~nm}$. Insulin samples were also separated by Native and SDS-PAGE on a Bio-Rad MiniProtean 3 system, using a 12\% separation gel and a $4 \%$ stacking gel. On Native-PAGE all buffers were prepared without SDS addition. Proteins were stained with Comassie Brilliant Blue [67].

\section{Circular dichroism and conformational stability measurements}

Secondary structure analysis was performed by far-UV $(185-260 \mathrm{~nm}) \mathrm{CD}$ in a Jasco J810 spectropolarimeter equipped with a temperature control unit Julabo F25 using an insulin concentration of $3 \mathrm{mg} \cdot \mathrm{ml}^{-1}$. Far UV CD spectra were recorded with $0.01 \mathrm{~cm}$ (linear) path length quartz cuvette at $37^{\circ} \mathrm{C}$ in $50 \mathrm{mM}$ sodium phosphate buffer pH 7.4 with $150 \mathrm{mM} \mathrm{NaF}$. For each spectrum, three scans were averaged and protein concentration was determined by absorbance at $275 \mathrm{~nm}$ using the above mentioned insulin extinction coefficient in a UV-Visible spectrophotometer Jasco V-530. For protein secondary structure estimation, CD spectra were deconvoluted using the CDSSTR [68] deconvolution algorithm on Dichroweb $[69,70]$. CD spectra of the appropriate buffers were recorded and subtracted from the protein spectra.

$\mathrm{CD}$ denaturation curves for non-glycated and glycated insulin monomer were constructed using the ellipticity at $222 \mathrm{~nm}$, monitored at $37^{\circ} \mathrm{C}$ after $24 \mathrm{~h}$ incubation with guanidinium hydrochloride $(\mathrm{GdnHCl})$ at various concentrations. The denaturation of glycated and nonglycated insulin could be described as sigmoidal curves and were analyzed according to a two-state unfolding model $\mathrm{M} \leftrightarrow \mathrm{U}$ using the linear extrapolation method [47] in a non-linear least squares fitting procedure and yielded values for $\Delta G_{-}^{\mathrm{O}}\left(\mathrm{H}_{2} \mathrm{O}\right)$, the conformational stability, and $\mathrm{m}$, the dependence of $\Delta \mathrm{G}_{-}^{\mathrm{o}}$ on denaturant concentration. $\mathrm{Cm}$, the denaturant concentration at the midpoint of the unfolding transition was calculated as $C_{m}=G_{-}^{o}\left(H_{2} \mathrm{O}\right) / m$. Denaturation curves for monomeric species were analyzed considering the equation developed by Santoro \& Bolen [71,72].

\section{Additional material}

Additional file 1: Figure S1. Evaluation of insulin aggregation in non-stirring conditions. Insulin incubation in $50 \mathrm{mM}$ potassium

phosphate buffer, $\mathrm{pH} 7.4$ supplemented with $150 \mathrm{mM}$ of $\mathrm{NaF}$, at $37^{\circ} \mathrm{C}$ in sterile conditions without stirring. Gel filtration experiments show that insulin does not aggregate in this incubation conditions, remaining in the monomeric form.

Abbreviations

a-CHCA: a-cyano-4-hydroxicinamic acid; Aß: $\beta$-amyloid peptide; AGE: Advanced glycation end-products; CD: Circular dichroism; CID: Collision 
induced dissociation; FAP: Familial amyloidotic polyneuropathy; $\mathrm{GdnHCl}$ : Guanidinium hydrochloride; MALDI: Matrix-assisted laser-desorption ionization; MAGE: Methylglyoxal-derived advanced glycation end-products; MGH: Hydroimidazolone; MGO: Methylglyoxal; MOLD: Methylglyoxal lysine dimer; RAGE: Receptor for advanced glycation end-products; SEC: Size exclusion chromatography; THP: tetrahydropyrimidine; ThT: Thioflavin T; TOF: Time of flight.

\section{Acknowledgements}

We thank Dr. Carlos Cordeiro for the gift of the methylglyoxal and Dr. Ram Nagaraj for the gift of the anti-MAGE antibody. We wish to acknowledge Dr. Carlos Cordeiro, Professor Ana Ponces Freire and Dr. Tiago F. Outeiro for helpful discussions and all the assistance provided. This work was supported by grants (PTDC/QUI/73430/2006), SFRH/BD/23604/2005 (L.M.A.O) and SFRH/ BPD/41037/2007 (R.A.G.) from the Fundação para a Ciência e a Tecnologia, Ministério da Ciência e Tecnologia, Portugal.

\section{Author details}

${ }^{1}$ Centro de Investigação Interdisciplinar Egas Moniz, Instituto Superior das Ciências da Saúde Egas Moniz, Campus Universitário, Monte da Caparica 2829-511 Caparica, Portugal. ²Centro de Química e Bioquímica, Departamento de Química e Bioquímica, Faculdade de Ciências da Universidade de Lisboa, Edifício C8, 1749-016 Lisboa, Portugal. ${ }^{3}$ Departamento de Análises Clínicas e Saúde Pública, Escola Superior de Saúde Dr. Lopes Dias, Instituto Politécnico de Castelo Branco, Campus da Talagueira 6000-767 Castelo Branco, Portugal. ${ }^{4}$ Instituto de Tecnologia Química e Biológica. Universidade Nova de Lisboa, 2780-901 Oeiras, Portugal.

\section{Authors' contributions}

LMAO conceived the part of the study related with the fibrillation kinetics of insulin, carried out part of the experimental procedures and was mainly responsible for the experimental setup and data analysis as well as the initial drafting of the manuscript. AL is responsible for executing most part of the experiments. RAG conceived, executed and interpreted the experiments related with mass spectrometry and participated in the writing of the manuscript. HN executed the experiments associated to the thioflavin $T$ curves. CF participated in the experiments to prove the nature of insulin aggregates. AVC contributed to this work with her expertise concerning mass spectrometry. AQ designed and coordinated the study and was mainly involved in the preparation and reviewing of the manuscript. All authors read and approved the final manuscript.

Received: 14 April 2011 Accepted: 5 August 2011

Published: 5 August 2011

\section{References}

1. Shepherd PR, Kahn BB: Glucose transporters and insulin actionimplications for insulin resistance and diabetes mellitus. $N$ Engl J Med 1999, 341(4):248-257.

2. Taylor R: Insulin action 1991. Clin Endocrinol (Oxf) 1991, 34(2):159-171.

3. Zierath JR, Krook A, Wallberg-Henriksson H: Insulin action and insulin resistance in human skeletal muscle. Diabetologia 2000, 43(7):821-835.

4. Baker EN, Blundell TL, Cutfield JF, Cutfield SM, Dodson EJ, Dodson GG, Hodgkin DM, Hubbard RE, Isaacs NW, Reynolds CD, Sakabe K, Sakabe N, Vijayan NM: The structure of $2 \mathrm{Zn}$ pig insulin crystals at $1.5 \mathrm{~A}$ resolution. Philos Trans R Soc Lond B Biol Sci 1988, 319(1195):369-456.

5. Blundell TL, Cutfield JF, Cutfield SM, Dodson EJ, Dodson GG, Hodgkin DC, Mercola DA: Three-dimensional atomic structure of insulin and its relationship to activity. Diabetes 1972, 21(2 Suppl):492-505.

6. Nystrom FH, Quon MJ: Insulin signalling: metabolic pathways and mechanisms for specificity. Cell Signal 1999, 11(8):563-574.

7. Ottensmeyer FP, Beniac DR, Luo RZ, Yip CC: Mechanism of transmembrane signaling: insulin binding and the insulin receptor. Biochemistry 2000, 39(40):12103-12112.

8. Ahmad A, Uversky VN, Hong D, Fink AL: Early events in the fibrillation of monomeric insulin. J Biol Chem 2005, 280(52):42669-42675.

9. Brange J, Andersen L, Laursen ED, Meyn G, Rasmussen E: Toward understanding insulin fibrillation. J Pharm Sci 1997, 86(5):517-525.

10. Westermark P, Benson MD, Buxbaum JN, Cohen AS, Frangione B, Ikeda S, Masters CL, Merlini G, Saraiva MJ, Sipe JD: Amyloid: toward terminology clarification. Report from the Nomenclature Committee of the International Society of Amyloidosis. Amyloid 2005, 12(1):1-4.

11. Dische FE, Wernstedt C, Westermark GT, Westermark P, Pepys MB, Rennie JA, Gilbey SG, Watkins PJ: Insulin as an amyloid-fibril protein at sites of repeated insulin injections in a diabetic patient. Diabetologia 1988, 31(3):158-161.

12. Storkel S, Schneider HM, Muntefering $H$, Kashiwagi S: latrogenic, insulindependent, local amyloidosis. Lab Invest 1983, 48(1):108-111.

13. Wilhelm KR, Yanamandra K, Gruden MA, Zamotin V, Malisauskas M, Casaite V, Darinskas A, Forsgren L, Morozova-Roche LA: Immune reactivity towards insulin, its amyloid and protein $\mathrm{S} 100 \mathrm{~B}$ in blood sera of Parkinson's disease patients. Eur J Neurol 2007, 14(3):327-334.

14. Jimenez JL, Nettleton EJ, Bouchard M, Robinson CV, Dobson CM, Saibil HR The protofilament structure of insulin amyloid fibrils. Proc Natl Acad Sci USA 2002, 99(14):9196-9201.

15. Vestergaard B, Groenning M, Roessle M, Kastrup JS, van de Weert M, Flink JM, Frokjaer S, Gajhede M, Svergun Dl: A helical structural nucleus is the primary elongating unit of insulin amyloid fibrils. PLOS Biol 2007, 5(5): e134.

16. Brownlee M: Biochemistry and molecular cell biology of diabetic complications. Nature 2001, 414(6865):813-820.

17. Abdel-Wahab YH, O'Harte FP, Ratcliff H, McClenaghan NH, Barnett CR, Flatt PR: Glycation of insulin in the islets of Langerhans of normal and diabetic animals. Diabetes 1996, 45(11):1489-1496.

18. Brownlee M: Advanced protein glycosylation in diabetes and aging. Annu Rev Med 1995, 46:223-234.

19. Lyons TJ, Silvestri G, Dunn JA, Dyer DG, Baynes JW: Role of glycation in modification of lens crystallins in diabetic and nondiabetic senile cataracts. Diabetes 1991, 40(8):1010-1015.

20. Miyata T, Ueda Y, Saito A, Kurokawa K: 'Carbonyl stress' and dialysisrelated amyloidosis. Nephrol Dial Transplant 2000, 15(Suppl 1):25-28.

21. Kume S, Takeya M, Mori T, Araki N, Suzuki H, Horiuchi S, Kodama T, Miyauchi Y, Takahashi K: Immunohistochemical and ultrastructural detection of advanced glycation end products in atherosclerotic lesions of human aorta with a novel specific monoclonal antibody. Am J Pathol 1995, 147(3):654-667.

22. Bucala R, Cerami A: Advanced glycosylation: chemistry, biology, and implications for diabetes and aging. Adv Pharmacol 1992, 23:1-34.

23. Vitek MP, Bhattacharya K, Glendening JM, Stopa E, Vlassara H, Bucala R, Manogue K, Cerami A: Advanced glycation end products contribute to amyloidosis in Alzheimer disease. Proc Natl Acad Sci USA 1994, 91(11):4766-4770.

24. Yan SD, Chen X, Schmidt AM, Brett J, Godman G, Zou YS, Scott CW, Caputo C, Frappier T, Smith MA, Perry G, Yen SH, Stern D: Glycated tau protein in Alzheimer's disease: a mechanism for induction of oxidant stress. Proc Natl Acad Sci USA 1994, 91(16):7787-7791.

25. Chen F, Wollmer MA, Hoerndli F, Munch G, Kuhla B, Rogaev El, Tsolaki M, Papassotiropoulos A, Gotz J: Role for glyoxalase I in Alzheimer's disease. Proc Natl Acad Sci USA 2004, 101(20):7687-7692.

26. Castellani R, Smith MA, Richey PL, Perry G: Glycoxidation and oxidative stress in Parkinson disease and diffuse Lewy body disease. Brain Res 1996, 737(1-2):195-200

27. Gomes R, Sousa Silva M, Quintas A, Cordeiro C, Freire A, Pereira P, Martins A, Monteiro E, Barroso E, Ponces Freire A: Argpyrimidine, a methylglyoxal-derived advanced glycation end-product in familial amyloidotic polyneuropathy. Biochem J 2005, 385(Pt 2):339-345.

28. Richard JP: Mechanism for the formation of methylglyoxal from triosephosphates. Biochem Soc Trans 1993, 21(2):549-553.

29. Chen K, Maley J, Yu PH: Potential inplications of endogenous aldehydes in beta-amyloid misfolding, oligomerization and fibrillogenesis. J Neurochem 2006, 99(5):1413-1424.

30. Jia $X$, Olson DJ, Ross AR, Wu L: Structural and functional changes in human insulin induced by methylglyoxal. FASEB J 2006, 20(9):1555-1557.

31. Gomes RA, Sousa Silva M, Vicente Miranda H, Ferreira AE, Cordeiro CA, Freire AP: Protein glycation in Saccharomyces cerevisiae. Argpyrimidine formation and methylglyoxal catabolism. FEBS J 2005, 272(17):4521-4531

32. Gomes RA, Oliveira LM, Silva M, Ascenso C, Quintas A, Costa G, Coelho AV, Sousa Silva M, Ferreira AE, Ponces Freire A, Cordeiro C: Protein glycation in vivo: functional and structural effects on yeast enolase. Biochem J 2008, 416(3):317-326. 
33. O'Harte FP, Hojrup P, Barnett CR, Flatt PR: Identification of the site of glycation of human insulin. Peptides 1996, 17(8):1323-1330.

34. Guedes S, Vitorino R, Domingues MR, Amado F, Domingues P: Mass spectrometry characterization of the glycation sites of bovine insulin by tandem mass spectrometry. J Am Soc Mass Spectrom 2009, 20(7):1319-1326

35. Lo TW, Westwood ME, McLellan AC, Selwood T, Thornalley PJ: Binding and modification of proteins by methylglyoxal under physiological conditions. A kinetic and mechanistic study with $\mathrm{N}$ alpha-acetylarginine, $\mathrm{N}$ alpha-acetylcysteine, and $\mathrm{N}$ alpha-acetyllysine, and bovine serum albumin. J Biol Chem 1994, 269(51):32299-32305.

36. Jarrett JT, Lansbury PT Jr: Amyloid fibril formation requires a chemically discriminating nucleation event: studies of an amyloidogenic sequence from the bacterial protein OsmB. Biochemistry 1992, 31(49):12345-12352.

37. Jarrett JT, Lansbury PT Jr: Seeding "one-dimensional crystallization" of amyloid: a pathogenic mechanism in Alzheimer's disease and scrapie? Cell 1993, 73(6):1055-1058.

38. Lomakin A, Teplow DB, Kirschner DA, Benedek GB: Kinetic theory of fibrillogenesis of amyloid beta-protein. Proc Natl Acad Sci USA 1997, 94(15):7942-7947.

39. Wood SJ, Wypych J, Steavenson S, Louis JC, Citron M, Biere AL: alphasynuclein fibrillogenesis is nucleation-dependent. Implications for the pathogenesis of Parkinson's disease. J Biol Chem 1999, 274(28):19509-19512.

40. Nielsen L, Frokjaer S, Brange J, Uversky VN, Fink AL: Probing the mechanism of insulin fibril formation with insulin mutants. Biochemistry 2001, 40(28):8397-8409.

41. Munishkina LA, Ahmad A, Fink AL, Uversky VN: Guiding protein aggregation with macromolecular crowding. Biochemistry 2008, 47(34):8993-9006.

42. Lashuel HA, Lansbury PT Jr: Are amyloid diseases caused by protein aggregates that mimic bacterial pore-forming toxins? Q Rev Biophys 2006, 39(2):167-201.

43. Chellan P, Nagaraj RH: Protein crosslinking by the Maillard reaction: dicarbonyl-derived imidazolium crosslinks in aging and diabetes. Arch Biochem Biophys 1999, 368(1):98-104.

44. Verzijl N, DeGroot J, Ben ZC, Brau-Benjamin O, Maroudas A, Bank RA, Mizrahi J, Schalkwijk CG, Thorpe SR, Baynes JW, Bijlsma JW, Lafeber FP, Tekoppel JM: Crosslinking by advanced glycation end products increases the stiffness of the collagen network in human articular cartilage: a possible mechanism through which age is a risk factor for osteoarthritis. Arthritis Rheum 2002, 46(1):114-123.

45. Nagaraj RH, Shipanova IN, Faust FM: Protein cross-linking by the Maillard reaction. Isolation, characterization, and in vivo detection of a lysinelysine cross-link derived from methylglyoxal. J Biol Chem 1996, 271(32):19338-19345

46. Ahmed N, Thornalley PJ: Peptide mapping of human serum albumin modified minimally by methylglyoxal in vitro and in vivo. Ann N Y Acad Sci 2005, 1043:260-266.

47. Pace CN: Determination and analysis of urea and guanidine hydrochloride denaturation curves. Methods in enzymology 1986, 131:266-280.

48. Myers JK, Pace CN, Scholtz JM: Denaturant $m$ values and heat capacity changes: relation to changes in accessible surface areas of protein unfolding. Protein Sci 1995, 4(10):2138-2148.

49. Ledesma MD, Bonay P, Colaco C, Avila J: Analysis of microtubuleassociated protein tau glycation in paired helical filaments. J Biol Chem 1994, 269(34):21614-21619

50. Loske C, Gerdemann A, Schepl W, Wycislo M, Schinzel R, Palm D, Riederer P, Munch G: Transition metal-mediated glycoxidation accelerates cross-linking of beta-amyloid peptide. Eur J Biochem 2000, 267(13):4171-4178.

51. Smith MA, Taneda S, Richey PL, Miyata S, Yan SD, Stern D, Sayre LM, Monnier VM, Perry G: Advanced Maillard reaction end products are associated with Alzheimer disease pathology. Proc Natl Acad Sci USA 1994, 91(12):5710-5714.

52. Munch G, Luth HJ, Wong A, Arendt T, Hirsch E, Ravid R, Riederer P: Crosslinking of alpha-synuclein by advanced glycation endproducts-an early pathophysiological step in Lewy body formation? J Chem Neuroanat 2000, 20(3-4):253-257.
53. Hashimoto N, Naiki H, Gejyo F: Modification of beta 2-microglobulin with D-glucose or 3-deoxyglucosone inhibits $\mathrm{A}$ beta $2 \mathrm{M}$ amyloid fibril extension in vitro. Amyloid 1999, 6(4):256-264.

54. Lee D, Park CW, Paik SR, Choi KY: The modification of alpha-synuclein by dicarbonyl compounds inhibits its fibril-forming process. Biochim Biophys Acta 2009, 1794(3):421-430.

55. Chen L, Wei Y, Wang X, He R: Ribosylation rapidly induces alphasynuclein to form highly cytotoxic molten globules of advanced glycation end products. PLoS One 2010, 5(2):e9052..

56. Ivanova MI, Sievers SA, Sawaya MR, Wall JS, Eisenberg D: Molecular basis for insulin fibril assembly. Proc Natl Acad Sci USA 2009, 106(45):18990-18995.

57. Caughey B, Lansbury PT: Protofibrils, pores, fibrils, and neurodegeneration: separating the responsible protein aggregates from the innocent bystanders. Annu Rev Neurosci 2003, 26:267-298.

58. Crowther DC, Kinghorn KJ, Miranda E, Page R, Curry JA, Duthie FA, Gubb DC, Lomas DA: Intraneuronal Abeta, non-amyloid aggregates and neurodegeneration in a Drosophila model of Alzheimer's disease. Neuroscience 2005, 132(1):123-135.

59. Danzer KM, Haasen D, Karow AR, Moussaud S, Habeck M, Giese A, Kretzschmar H, Hengerer B, Kostka M: Different species of alpha-synuclein oligomers induce calcium influx and seeding. J Neurosci 2007, 27(34):9220-9232.

60. Lauren J, Gimbel DA, Nygaard HB, Gilbert JW, Strittmatter SM: Cellular prion protein mediates impairment of synaptic plasticity by amyloidbeta oligomers. Nature 2009, 457(7233):1128-1132.

61. Bierhaus A, Stern DM, Nawroth PP: RAGE in inflammation: a new therapeutic target? Curr Opin Investig Drugs 2006, 7(11):985-991.

62. Maczurek A, Shanmugam K, Munch G: Inflammation and the redoxsensitive AGE-RAGE pathway as a therapeutic target in Alzheimer's disease. Ann N Y Acad Sci 2008, 1126:147-151.

63. Brange J: Galenics of insulin. The physicochemical and pharmaceutical aspects of insulin and insulin preparations. Berlin: Springer-Verlag; 1987.

64. Groenning M, Frokjaer S, Vestergaard B: Formation mechanism of insulin fibrils and structural aspects of the insulin fibrillation process. Curr Protein Pept Sci 2009, 10(5):509-528.

65. Naiki H, Higuchi K, Hosokawa M, Takeda T: Fluorometric determination of amyloid fibrils in vitro using the fluorescent dye, thioflavin T1. Analytical biochemistry 1989, 177(2):244-249.

66. Naiki H, Higuchi K, Matsushima K, Shimada A, Chen WH, Hosokawa M, Takeda T: Fluorometric examination of tissue amyloid fibrils in murine senile amyloidosis: use of the fluorescent indicator, thioflavine T. Lab Invest 1990, 62(6):768-773.

67. Wilson CM: Studies and critique of Amido Black 10B, Coomassie Blue R, and Fast Green FCF as stains for proteins after polyacrylamide gel electrophoresis. Analytical biochemistry 1979, 96(2):263-278.

68. Johnson WC: Analyzing protein circular dichroism spectra for accurate secondary structures. Proteins 1999, 35(3):307-312.

69. Lobley A, Whitmore L, Wallace BA: DICHROWEB: an interactive website for the analysis of protein secondary structure from circular dichroism spectra. Bioinformatics (Oxford, England) 2002, 18(1):211-212.

70. Whitmore L, Wallace BA: DICHROWEB, an online server for protein secondary structure analyses from circular dichroism spectroscopic data. Nucleic acids research 2004, 32 Web Server: W668-673.

71. Bolen DW, Santoro MM: Unfolding free energy changes determined by the linear extrapolation method. 2. Incorporation of delta $\mathrm{G}$ degrees $\mathrm{N}-\mathrm{U}$ values in a thermodynamic cycle. Biochemistry 1988, 27(21):8069-8074.

72. Santoro MM, Bolen DW: Unfolding free energy changes determined by the linear extrapolation method. 1. Unfolding of phenylmethanesulfonyl alpha-chymotrypsin using different denaturants. Biochemistry 1988, 27(21):8063-8068.

doi:10.1186/1471-2091-12-41

Cite this article as: Oliveira et al:: Insulin glycation by methylglyoxal results in native-like aggregation and inhibition of fibril formation. $B M C$ Biochemistry 2011 12:41. 